\title{
Teaching linguistic politeness: A methodological proposal ${ }^{*}$
}

\author{
PATRICIA BOU-FRANCH AND PILAR GARCÉS-CONEJOS
}

\begin{abstract}
The aim of this article is to explore theoretical and methodological aspects of the teaching of pragmatics in a second language. Taking as point of departure the pragmatic continuum, which includes pragmalinguistics and sociopragmatics, we focus on the promotion of sociopragmatic knowledge in classroom contexts. More specifically, it is argued that a revised contextual and interactional view of Brown and Levinson's (1987) model of linguistic politeness, related to such notions as genre and politeness systems, offers suitable tools of pragmatic description for use in teaching and learning second languages. We start with a brief overview of linguistic politeness from a socio-cognitive framework. Then, we revise the main methodological approaches to the teaching of pragmatic knowledge in general and the specific teaching of linguistic politeness in particular. Finally, we make a methodological proposal for use in foreign language instruction.
\end{abstract}

\section{Introduction}

For years, there has been great neglect as regards the role and the teaching of conversation in foreign language instruction. Gradually, more researchers are becoming interested in structuring conversation classes and designing appropriate methodologies and sequenced teaching materials (e.g., Richards 1990; Dörnyei and Thurrell 1994; Celce-Murcia et al. 1995; Bou-Franch 2001).

The aim of this article is to explore theoretical and methodological aspects of teaching linguistic politeness as a means of promoting language learners' pragmatic competence. Pragmatic competence has been claimed to be "the most difficult aspect of language to master in learning a second language" (BlumKulka and Sheffer 1993: 219). Besides, we believe that "without some form of instruction, many aspects of pragmatic competence do not develop sufficiently" (Kasper 1997: 3).

IRAL 41 (2003), 1-22

0019042X/2003/041-01

(c) Walter de Gruyter 


\section{Patricia Bou-Franch and Pilar Garcés-Conejos}

Thomas (1983: 92) affirms that an individual's linguistic competence consists of grammatical competence and pragmatic competence; the latter is defined as "the ability to use language effectively in order to achieve a specific purpose and to understand language in context". Leech (1983) and Thomas (1983) put forth a pragmatic continuum that includes pragmalinguistics at the more linguistic end and sociopragmatics at the social end. We take this pragmatic continuum as the general framework for our work in developing pragmatic competence (see Bachman's [1990] illocutionary and sociolinguistic components of linguistic communication).

Pragmalinguistics refers to "the particular resources which a given language provides for conveying particular illocutions" (Leech 1983: 11), while sociopragmatics, the end of the pragmatic continuum closest to society and the world, is related to our sociolinguistic knowledge and refers to what constitutes socially appropriate linguistic behaviour. Sociopragmatics is related to Kerbrat-Orecchioni's (1997) relational level of interaction and it constitutes the present object of study. We shall argue in favour of using a contextual and interactional version of Brown and Levinson's (1987) model of linguistic politeness in promoting sociolinguistic knowledge. Brown and Levinson's study of politeness in terms of linguistic strategies is combined with Fraser's (1980, 1990) and Fraser and Nolen's (1981) view of politeness as social appropriateness, and with Garcés-Conejos' (1991, 1995) discursive and interactional orientation of politeness as the encoding of social relations. The two views of politeness as (i) linguistic strategies, and (ii) contextual appropriateness are combined and viewed from a discursive and socio-cognitive framework. Sociopragmatics, then, is seen as part of human social cognition since it is related to our knowledge, beliefs and perceptions of socially adequate linguistic behaviour. The resulting framework, it will be argued, offers suitable tools to enhance sociopragmatics in a second language, following the main methodological points made by researchers in the area of the teaching and acquisition of pragmatic competence (e.g., Bialystok 1993; Kasper 1997; Richards 1990; Schmidt 1993).

Little work has been done on the explicit teaching of sociopragmatic knowledge and the presentation of exercises for use in the classroom (Bou-Franch 2001; Garcés-Conejos 2001; Garcés-Conejos et al. 1992; Gómez-Morón 2001; Meier 1997). However, language teachers cannot overlook the consequences that failure or misunderstandings at this level can have for the presentation of self and the interpretation of other (Richards and Schmidt 1983; Bou-Franch and Garcés-Conejos 1994). Thomas (1983: 96-97) underlines the importance of pragmatic failure by comparing it with grammatical errors:

Grammatical errors may be irritating and impede communication, but at least, as a rule, they are apparent in the surface structure, so that $\mathrm{H}$ [the hearer] is aware 
that an error has occurred. Once alerted to the fact that $S$ [the speaker] is not fully grammatically competent, native speakers seem to have little difficulty in making allowances for it. Pragmatic failure, on the other hand, is rarely recognized as such by non-linguists. If a non-native speaker appears to speak fluently (i.e., is grammatically competent), a native speaker is likely to attribute his/her apparent impoliteness or unfriendliness, not to any linguistic deficiency, but to boorishness or ill-will. While grammatical error may reveal a speaker to be a less than proficient language-user, pragmatic failure reflects badly on him/her as a person.

In this article we attempt to examine the teaching of sociolinguistic knowledge in foreign language instruction. We make proposals that will help students make appropriate decisions and informed choices at the level of production and interpretation of linguistic communication in different situations, and which will help, therefore, to avoid sociopragmatic failure. To achieve this, we start with a brief overview of linguistic politeness theory. Then, we revise the main methodological positions with reference to the teaching of pragmatic knowledge in general. This is followed by the teaching of linguistic politeness. We shall argue in favour of relating our view of politeness to genre studies and to the notion of politeness systems put forth by Scollon and Scollon (1995). Finally, we make a methodological proposal for the teaching of politeness in classroom contexts.

\section{Brief overview of linguistic politeness}

Although there have been several approaches to the study of linguistic politeness (Lakoff 1973; Fraser 1980; Fraser and Nolen 1981; Leech 1983; Brown and Levinson 1987), ${ }^{1}$ we believe that a discursive and interactional (and therefore, contextual) re-interpretation of Brown and Levinson's (1987) model constitutes the most suitable way of pursuing this issue. ${ }^{2}$ In our framework, politeness is seen as related to social appropriateness, addressing expectations that individuals have as part of their social cognition in particular contexts of interaction (Garcés-Conejos and Bou-Franch to appear). Social cognition is understood in terms of the mental processes and structures that shape and are shaped by interpersonal knowledge and schemas (McCann and Higgins 1990: 15). Politeness can be defined as the linguistic encoding of social relations that individuals establish in interaction; these reflect participants' socio-cognitive perceptions and expectations (Brown and Levinson 1987; Garcés-Conejos 1995). This socio-cognitive view of politeness in interaction links the approach that considers politeness as social judgements or adequacy and the approach that considers politeness in terms of linguistic strategies. Three important points are that social relations are negotiable, that the politeness value of linguistic forms is always relative and has to be interpreted in particular contexts and, 
finally, that politeness has to be communicated and interpreted by the audience as such (Fraser 1990; Garcés-Conejos 1995).

Brown and Levinson's (1987) account stems from the concept of a model person endowed with rationality (and therefore capable of means-end reasoning) and face. Face, a universal but culturally elaborated construct, refers to the public self-image that every competent adult member of society claims for him/herself. Face has two related aspects: negative face - basically, the expression of restraint and independence, usually associated with popular notions of formal politeness; and positive face - roughly, the expression of involvement or belonging in a group, which includes the desire to be "ratified, understood, approved of, liked or admired" (Brown and Levinson 1987: 62). Following Brown and Levinson (1987: 62):

Negative face is the want of every 'competent adult member' that his actions be unimpeded by others.

Positive face is the want of every member that his wants be desirable to at least some others.

Face can be maintained, enhanced or lost during interaction. Since face is understood in terms of wants to be fulfilled by others, it is in everyone's interest to constantly monitor and attend to face in interaction.

Another central notion in Brown and Levison's (1987) approach refers to what they call face threatening acts: acts whose propositional content threatens or runs contrary to the face wants of participants in an interaction, more specifically, face threatening acts may threaten the speaker's or the hearer's positive or negative face needs.

This theory, then, encompasses the social constraints which the speaker is faced with in interaction and which, as explained above, are part of our social cognition. In performing a face threatening act, unless the situation requires maximum efficiency or urgency, the speaker will decide to minimize the possible face threat. Brown and Levinson (1987: 60) identify five superstrategies or general behaviour patterns that the speaker can follow in the performance of a face threatening act (FTA):

1. Do the FTA without redressive action: baldly on record.

2. Do the FTA with redressive action: positive politeness.

3. Do the FTA with redressive action: negative politeness.

4. Do the FTA off record.

5. Do not do the FTA.

The first four strategies represent alternative means of expressing the same propositional content of a face threatening act (e.g., the speaker wants the hearer to open the door). Doing an act on record, baldly without redress implies realizing it in the clearest and most unequivocal way, in accordance with the maxims, e.g., Close the door. Alternatively, the speaker may decide to use redressive action. This can be of two types: positive politeness, by means of 
which the speaker expresses solidarity and involvement, suggesting that the speaker wants the same as the hearer; or negative politeness, the expression of deference where the speaker respects the hearer's territory and does not want to curtail the hearer's freedom of action, e.g., Close the door, Nicky and Do you think you could close the door?, respectively. The speaker goes off record when the face threatening act is expressed ambiguously via conversational implicatures à la Grice (Grice 1975). In these cases, more than one intention is attributable to the speaker, and as a result, the hearer needs to make a more complicated inference. Besides, the speaker can always deny and cancel the implicature, e.g., There's a terrible draught in here.

The speaker will choose among the above strategies depending on the following sociological variables: power, social distance and ranking of imposition. ${ }^{3}$ Power (P), an asymmetrical notion, refers to the extent to which the hearer can impose his wishes and actions on the speaker; social distance (D) can be understood symmetrically as familiarity or closeness. Ranking of imposition in a particular culture $(\mathrm{R})$ refers to the relative rights that the speaker has to perform an act and the relative obligation of the hearer to comply.

Finally, Brown and Levinson (1987) posit a formula to calculate the seriousness of the face threatening act in each situation. The idea is that the more serious the act, the higher the number of the strategy choosen by the speaker. Higher-numbered strategies are seen as more polite than their lower-numbered counterparts. However, no such claim is being made here since empirical research has proved (i) that more than one type of strategy can be used in the performance of a face threatening act; and (ii) that there is no direct correlation between the overall seriousness of the act and the selection of a strategy (Garcés-Conejos 1991, 1995). Therefore, we cannot claim that one strategy is more polite than another. Given our socio-cognitive notion of politeness as contextual adequacy, a strategy will be polite to the extent that it is appropriate in a particular context of interaction. ${ }^{4}$ Furthermore, the strategies reflect the type of social relationship - in terms of power, social distance and affect, and imposition - established among participants on each particular occasion. We consider that politeness is pervasive, present in all discourse types and, instead of dealing with more or less polite individuals or discourses, we believe that different situations or discourse types require different forms of social relations and hence different linguistic means of politeness.

Politeness has to be communicated: that is, produced and interpreted. The interpretation of politeness belongs to the area of social cognition within the general "theory of mind" (Wilson 2000). Recent studies attempt to relate politeness theory to comprehension processes, more specifically, to those detailed by relevance theory (Escandell-Vidal 1998; Jary 1998). While relevance theory offers an excellent account of pragmatics as verbal comprehension, the study of the relationship between a social neo-Gricean approach like Brown and Levin- 


\section{Patricia Bou-Franch and Pilar Garcés-Conejos}

son's and relevance-theoretic accounts of cognition and communication is still in its infancy and in need of more research.

Nevertheless, from our socio-cognitive perspective on language use, Brown and Levinson's (1987) model still offers an excellent inventory of the linguistic forms used as a result of the socio-cognitive constraints participants are faced with in communication. Furthermore, we believe that recurrent patterns of use can be identified in different types of interaction. In this respect, we would like to elaborate on two related notions: genre and politeness systems. By using these notions, we attempt to use a dynamic model of linguistic politeness that overcomes prior criticism directed against Brown and Levinson for not considering the sequentiality of interaction or the type of discourse object of analysis (Garcés-Conejos 1991). Finally, these notions are very useful for teaching purposes, as we explain in Sections 4 and 5.

\section{Methodological approaches to teaching pragmatics}

While grammar constitutes the bulk of much traditional language teaching, pragmatics is still regarded as difficult to teach. Thomas (1983: 97) provides two good reasons that may account for this situation: (i) that pragmatic description is not as precise as grammar in accounting for linguistic competence; and (ii) that pragmatics is "a delicate area and it is not immediately obvious how it can be 'taught"'.

However, work in the 1990s has begun to shape methodologies suitable for teaching pragmatics. The best-known perspectives are those identified by Richards (1990: 76-77) in teaching conversation:

Currently there are two major approaches to the teaching of conversation in second language programs. One is an indirect approach, in which conversational competence is seen as the product of engaging learners in conversational interaction. The second, a more direct approach, involves planning a conversation program around the specific microskills, strategies, and processes that are involved in fluent conversation.

Therefore, the indirect approach implies that just by getting learners to interact, they will improve their knowledge of the language and their conversational skills, and so teachers need only provide opportunities for practising "natural" interaction with the help of communicative tasks and activities. As Richards (1990: 78) puts it "it is not necessary (or even possible) to teach conversation in any real sense".

We find three main objections to the indirect approach to teaching conversational knowledge. Firstly, researchers have not been able to specify in what ways classroom interaction relates to L2 learning, or what specific aspects of 
learning are facilitated by interaction (Alcón Soler 2000). Secondly, it follows from the indirect viewpoint that learners are expected to acquire sociopragmatic knowledge from interaction with native speakers - or very advanced learners. However, this type of knowledge is mainly unconscious for native speakers and their intuitions fallible (Schmidt 1993), so "it is vital that teaching materials on L2 pragmatics are research-based" (Kasper 1997: 7). Thirdly, Richards (1990) reports that the majority of tasks proposed in the indirect approach are based on transactional (message-oriented) discourse to the neglect of interactional (interpersonally-oriented) uses of the language (Brown and Yule 1983). This can have serious consequences since conversation, the prototype of interactional discourse, has been claimed to be the most basic form of language use against which we compare and learn other forms of spoken encounters.

Lakoff (1989: 102-103), for instance, states that ordinary conversation (OC) functions as a template for other forms of interaction "which we experience in terms of their similarities to and differences from OC, and feel more or less comfortable with to the degree that they conform to our OC-based expectations". Consequently, lack of practice of casual conversation can hinder our ability to participate in more transactionally-oriented encounters. Besides, we must not forget that speech events combine transactional and interactional uses of the language. Therefore, we agree with Richard's (1990: 74) claim that "the ability to produce this kind of casual conversational language as well as to produce language appropriate for more formal encounters is an essential skill for second language learners". We would like to add to this statement that learners must be able to not only produce appropriate interactional and transactional language, but also understand and interpret both uses of the language appropriately.

We believe, then, that we must take the direct approach to teaching pragmatic knowledge as a starting point, and combine it with exercises that practice directly-taught knowledge indirectly. This means that conversational skills should be explicitly taught and incorporated in the programme. Then, as Richards (1990) suggests, we can attempt to reach a balance between indirect and direct approaches and regard them not as mutually exclusive but as complementary.

In considering the direct and explicit teaching of pragmatic knowledge, the role of learners' conscious attention is essential for subsequent acquisition. Schmidt (1993: 21) understands that this approach "focuses explicitly on the strategies involved in conversation and emphasizes consciousness-raising concerning these strategies". Schmidt argues that exposure to adequate sociopragmatic input is not enough for learning to occur and affirms that in order to promote the acquisition of pragmatic competence, learners need to pay conscious attention to linguistic forms, their functional meanings and relevant features of 
the context. He also highlights the importance of the teacher in drawing learners' attention to the information to be acquired:

Explicit teacher-provided information about the pragmatics of the second language can also play a role in learning, provided that it is accurate and not based solely on fallible native speaker intuitions. Explicit teaching is often more efficient than attention to input for identifying the pragmalinguistic forms of the target language. (Schmidt 1993: 36)

The idea of developing in the student some metapragmatic ability understood in terms of "the ability to analyse language use in a conscious manner" has already been put forth by Thomas (1983: 98). Another cognitive approach to the acquisition of pragmatic knowledge is that of Bialystok (1993) who states that adults sometimes make pragmatic errors despite their knowledge of the form, structure and vocabulary needed to express intentions. Bialystok explains this with her notion of control of processing, which is a complex skill needed in utterance comprehension and production. She has noted that learners often "fail to attend to a social distinction that needs to be marked linguistically, or they select the incorrect politeness marker for the situation or the listener" (Bialystock 1993: 54). In Kasper's (1997: 2) words, learners "don't always use what they know".

Having emphasized the importance of conscious attention in teaching pragmatic knowledge, Schmidt suggests that teachers should develop specific awareness-raising tasks to direct learners' attention to the teaching objective and therefore activate the processes that facilitate acquisition. As to the teaching of sociopragmatic information in terms of linguistic politeness devices, we attempt to relate linguistic politeness theory to the notion of genre and that of politeness systems and to acknowledge the methodological issues explained so far in relation to teaching general pragmatic knowledge.

\section{Teaching linguistic politeness}

We consider linguistic politeness to have a central place in foreign language teaching. Brown and Yule's (1983) distinction between interactional and transactional discourse has sometimes been taken to imply that only interactionallyoriented discourses involve social relations, and that the interpersonal dimension is totally lacking, or only marginally present. However, in transactional discourses (Lakoff 1989), an interpersonal orientation has been empirically proven to be evident (see, among others, Garcés-Conejos and TorreblancaLópez 1997 for classroom discourse; Garcés-Conejos and Sánchez-Macarro 1998 for scientific discourse; Gómez-Morón 2001 for academic genres). As Scollon and Scollon (1995: 49) put it "there is no faceless communication". Therefore, L2 learners must be aware of the linguistic choices participants 
make in producing and interpreting messages under particular socio-cognitive constraints, in order to promote sociopragmatic awareness and improve production and comprehension of pragmalinguistic resources.

Findings from cross-cultural pragmatic research have shown that learners regularly perform speech acts such as requests, apologies, and refusals in accordance with the sociolinguistic norms of their native language as a result of pragmatic transfer. However, adult learners have fully developed sociolinguistic knowledge in their native language and therefore they:

[...] have been shown to display sensitivity towards context-external factors such as interlocutors' familiarity and relative status [...] and context-internal factors such as degree of imposition, legitimacy of the requestive goal and 'standardness' of the situation in requesting, and severity of offence, obligation to apologize, and likelihood of apology acceptance in apologizing. (Kasper 1992: 211-212)

We believe that enhancing learners' L1 sociolinguistic perceptions will facilitate awareness-raising of the differences and similarities in the linguistic expression of social relations across genres and cultures. Our proposal, then, highlights the relation between the two ends of the pragmatic continuum: developing L2 sociopragmatic knowledge will result in the improvement of the production and interpretation of L2 pragmalinguistic strategies. Foreign language teaching must be adjusted to incorporate a pragmatic perspective. In their study of diminutive forms in Spanish and their locutionary and illocutionary expression in English translations, Garcés-Conejos et al. (1992: 247) argue in favour of the adoption of a pragmatic perspective in foreign language teaching:

La enseñanza eficaz de lenguas debe ser planteada como algo más que la simple presentación y práctica de una serie de modelos fonéticos o morfosintácticos. Esos modelos lingüísticos deben ser contextualizados y relacionados con las situaciones en que podrían utilizarse con el fin de adecuarlos al marco sociológico de relaciones de los interlocutores de la lengua objeto. Los estudiantes de L2 sólo lograrán comunicarse correctamente cuando codifiquen sus mensajes utilizando las estructuras adecuadas en el contexto pertinente teniendo en cuenta a quién van dirigidas. Aceptar lo anterior implica que la enseñanza de lenguas tiene que ser enfocada desde una perspectiva pragmática.

[Efficient foreign language teaching must be taken to go beyond the mere presentation and practice of a series of phonetic and morpho-syntactic models. Linguistic models must be contextualized and related to the situations of use in order to adapt them to the sociological frame of relations among the interlocutors of the target language. L2 learners will communicate successfully only when they encode their messages by means of structures appropriate to the context of use and taking into account the intended addressee. Accepting this implies that foreign language teaching must be approached from a pragmatic standpoint] 
The authors claim that politeness theory offers adequate tools to teach linguistic forms in context. They conclude by highlighting that L2 learners must be able to not only express the propositional content of their messages, but also to adapt these to meet the requirements of social interaction, since failing to meet social parameters can lead to pragmatic failure (Thomas 1983) or even to communication breakdown.

With a view to teaching contextualized language, Gómez-Morón (2001) carries out a detailed analysis of citation methods in research papers. She underlines the importance of politeness theory in teaching academic writing and in making learners understand the importance of these mechanisms, as well as in making them realize why and when to use quotations of one type or another.

Garcés-Conejos (1993: 309) also affirms that politeness theory is beneficial not only for foreign language learners, but also for learners and teachers of literature since "las obras literarias son fiel exponente de la época y la sociedad en la que fueron creadas, y su lenguaje codifica la interacción social de la misma" [literary works are faithful exponents of the time and society in which they were created, and their language codifies the social interaction of their milieu].

Our view is that politeness theory offers the best tools for students to learn to make documented choices determined by the cultural and socio-cognitive constraints of the situation. However, we must remark that there is no general agreement on the validity of this approach. Meier (1997: 21), for example, in the line of many authors who have undervalued the potential of Brown and Levinson's (1987) model, argues that "research invoking Brown and Levinson's theory of politeness in order to determine 'rules of politeness' should not form the basis of the teaching of 'politeness phenomena' in foreign and second language pedagogy". Meier also criticizes cross-cultural speech act research that invokes Brown and Levinson's model and the results of this line of research for teaching purposes. More specifically, she complains that teaching materials have incorporated the results of studies which claim the existence of a small set of clear-cut politeness rules and strategies, despite the many criticisms that Brown and Levinson's model has received. To illustrate this viewpoint, Meier (1997: 22) warns of "[...] the imprudence of determining rules of politeness for teaching by drawing on research that uses their [Brown and Levinson's] framework".

Meier (1997) suggests that politeness should be defined as appropriateness. This being a situation-bound notion, no rules of politeness can be identified. Instead, and from an anthropological viewpoint, Meier focuses on awarenessraising of different expectations that depend on contextual factors. This consciousness-raising activity implies (i) "An understanding that different evaluations of appropriateness may exist across cultures" (Meier 1997: 24); and (ii) paying attention to contextual factors and their value in the L2 so that learners will be prepared to make informed choices in interaction and present their 
desired image. Meier (1997: 25) goes on to argue that hers is a dynamic approach whose aim is to "gain insight into cultural assumptions which underlie the perception of contextual and situational factors as they inform linguistic behaviour". She proposes three groups of activities which, additionally, address causes of pragmatic failure and negative transfer:

(i) Discussion of judgements of appropriateness in context in both cultures.

(ii) Avoidance of prescriptivism and use, instead, of learner observation, discussions and comparison of unsuccessful/successful dialogues to increase understanding of linguistic behaviour.

(iii) Modification of textbook dialogues and participation in role plays to raise students' awareness of the social and cultural factors that determine pragmalinguistic choices.

These activities, in turn, are designed to promote positive attitudes towards differences with the aim of fostering the elimination of cultural stereotyping. While the approach seems generally correct, and the contextual view of politeness coincides partly with our own, we still believe that Brown and Levinson's (1987) model plays a central role in raising learners' awareness of the linguistic reflections of socio-cultural differences. How can we expect learners to make judgements of social appropriateness in two cultures, without first providing them with the specific linguistic tools that enact social adequacy and open the way to analyse social interaction? Without these linguistic means, judgements of appropriateness will be based on intuition, not on linguistic enquiry. We believe that the notion of appropriateness is too vague to constitute a useful pedagogical guideline. Instead, we consider the two approaches to politeness - i.e., the contextual appropriateness view taken by Fraser (1990) and the linguistic strategy view taken by Brown and Levinson - to be complementary. The combination of both creates a useful and powerful tool from which both teachers and students can benefit enormously.

As we mentioned above, a cognitive and contextual reinterpretation of Brown and Levinson's model is in order, one in which linguistic forms are seen to have a relative value and in which social relations are considered negotiable (Fraser 1980, 1990; Fraser and Nolen 1981) and adaptable to participants' social expectations. In order to teach politeness, we have discussed the suitability of awareness-raising tasks in which the learners' attention focuses on the information to be acquired, which should be supplemented with pragmatic knowledge provided by the teacher. This information is best presented taking into account particular contexts or genres.

\section{Genre and politeness systems in foreign language teaching}

We have argued in favour of an approach to politeness that combines the contextual appropriateness view with the linguistic strategy. Pedagogically powerful as this combination is, we still believe it to be too broad to help students 
accurately predict what specific language production/interpretation is appropriate or should be expected from others. A useful methodology should aim at restricting, as much as possible, the range of choices speakers and hearers are faced with in interaction. In teaching politeness, this can be done by introducing a genre-based approach and by presenting learners with the notion of politeness systems (Scollon and Scollon 1995).

Following Carter and McCarthy (1995: 144), we believe that "a more genresensitive description of the spoken language" constitutes "the most useful resource for teachers and learners of English". In the specific teaching of politeness, we believe appropriateness to be constrained, among other things, by genre considerations. Therefore, it would be extremely useful for learners to study and apply the formal descriptive apparatus provided by Brown and Levinson's model against the background of different types of genre, oral and written, in which various degrees of formality would apply. In this way, students could observe how these matters affect politeness.

There are several approaches to the notion of genre. Gómez-Morón (1998) identifies three different traditions: (i) the American School of the New Rhetoric - or Rhetorical Genre Studies - (e.g., Freedman and Medway 1994; Miller 1984); (ii) Australian Systemic Functional Linguistics (e.g., Martin 1985); and (iii) English for Specific Purposes (e.g., Bhatia 1993; Swales 1990).

The first tradition, Rhetorical Genre Studies, emphasizes the dynamic nature of genres understood as "typified actions in response to recurring social contexts" (Freedman 1999: 764) which constrain communicative choice in a non-binding way. Freedman, representative of this tradition, argues against the usefulness of these methods in language teaching "except in a very limited form, as a way of consciousness-raising, during the actual process of students' response to particular exigencies" (Freedman 1999: 766). She also questions the plausibility of explaining to students the complexity of social, cultural and rhetorical features of genres.

On the other hand, Christie (1999), who belongs to the Australian Systemic Functional tradition which views genre as a staged activity that serves important social goals (Gómez-Morón 1998: 7), affirms that genres are useful in teaching English as a second language for several reasons. Among these, genres "offer a principled way to identify and focus upon different types of English texts" and provide students with "a sense of the generic models that are regularly revisited in an English-speaking culture" (Christie 1999: 762).

Finally, the tradition known as English for Specific Purposes considers genre as an appropriate tool to analyse spoken and written language use in professional and academic settings and claims that genre is a powerful teaching tool for non-native speakers of language. They view genres as defined by formal features as well as by their communicative intentions within a social context (Gómez-Morón 1998: 8). 
We share with the Australian Systemic Functional approach and the English for Specific Purposes approach the belief that we can provide students with a descriptive genre-sensitive framework that will help them acquire pragmatic knowledge. This view contrasts with that defended by Meier (1997) in teaching politeness (explained in section 4), in which students, though expected to make cultural assumptions and judgements of appropriateness of linguistic forms in social contexts, are not given descriptive means of analysis.

As Gómez-Morón (1998) points out, genres defined as structured communicative events and organized social processes have been used pedagogically, but mainly for the teaching of written texts in English for academic purposes. However, these studies have not followed a primarily pragmatic approach:

Aunque han considerado el aspecto comunicativo del lenguaje, en el sentido de que se refieren a la interacción existente entre autor y lector, no han resaltado suficientemente este aspecto, dando como resultado, en su mayoría, estudios formales. (Gómez-Morón 1998: 29)

[Though they have considered the communicative aspect of language, in the sense of taking into account the interaction established between the author and the reader, they have not highlighted pragmatic aspects enough. As a result, they constitute primarily formal studies.]

It is also mainly formal and structural studies that we find in generic approaches to casual conversation or other forms of spoken interaction. For example, Schegloff (1999: 412) mentions the following generic issues that constitute casual conversation:

Returning now to the concern that conversation is a merely residual category with no affirmative, constitutive features of its own, one can say that 'conversation' is talk-in-interaction produced by the participants' orientation to, and implementation of, the generic organizations for conversation: for example, by an orientation to the turn-taking, repair, sequence and the overall structural organizations for conversation (and very likely others as well).

Without a doubt, by studying the turn-taking, repair and sequence organizations of speech events one can identify important generic features of a formal nature, equivalent to Kerbrat-Orecchioni's (1997) organizational level. For example, Gregori-Signes (2000) analyses US tabloid talk-shows as a quasiconversational genre based on a revision of the formal and structural features recurrent in a particular communicative situation. In this way, the author follows McCarthy and Carter (1994: 24) who take genres to capture the "idea that there may be underlying recurrent features which are prototypically present in particular groups of texts".

We hold that these formal features, however, are subservient to socio-cognitive constraints and believe, therefore, that other approaches should comple- 
ment studies at the organizational level by analysing different types of linguistic forms whose recurrence is associated with the linguistic encoding of the social relationship of participants (i.e., politeness) in a given context, i.e., the relational level of study (Kerbrat-Orecchioni 1997). This level of study can be linked to the notion of the 'recipient design' of turns (Sacks et al. 1974: 727), understood as a general principle which particularizes conversational interaction:

By 'recipient design' we refer to a multitude of respects in which the talk by a party in a conversation is constructed or designed in ways which display an orientation and sensitivity to the particular other(s) who are the co-participants. In our work, we have found recipient design to operate with regard to word selection, topic selection, admissibility and ordering of sequences, options and obligations for starting and terminating conversations, etc.

In our opinion, the socio-cognitive account of linguistic politeness theory offers powerful explanatory tools of social interaction and emerges as the appropriate viewpoint from which to analyse turns' 'recipient design', or the relational level of communication. Moreover, politeness theory constitutes a suitable model that explains social interaction within and across genres.

In sum, we advocate the need to analyse genres from both a formal and structural standpoint and from a pragmatic approach. In this sense, GarcésConejos and Sánchez-Macarro (1998: 189) analyse the genre of scientific discourse from the viewpoint of social interaction and underline the importance of taking into account social and cognitive constraints in understanding the configuration of genres:

Matters of genre need not only be discussed from a formal stand point. The configuration and contents of texts can largely be explained in terms of the writer/reader interaction they embody. Politeness theory presents itself as the right tool for such an endeavour.

Gómez-Morón (1998) takes the above study as point of departure and follows the pragmatic theory of politeness in her study of medical and linguistic research papers.

Having highlighted the importance of relating linguistic politeness theory to genre analysis as a meaningful way of constraining communicative choice in different culture-bound situations, the notion of politeness systems put forth by Scollon and Scollon (1995) emerges as the second means of providing students with a more restricted framework for the understanding and assessment of the sociological variables: power, distance and ranking of imposition; and also for the choice of the appropriate or expected set of strategies they should select to codify their social interaction. 
Scollon and Scollon (1995: 33-49) identify three politeness systems that capture the general and persistent regularities in face relationships: a deference politeness system, a solidarity politeness system and a hierarchical politeness system:

(i) Deference politeness system $(-\mathrm{P},+\mathrm{D})$ : Social relations between participants are considered symmetrical, since there is no power differential and therefore they regard each other as equals. However, despite the fact that participants are at the same social level, there is social distance between them, that is, there is no closeness. Accordingly, each participant uses independence strategies (negative politeness in Brown and Levinson's terms) in addressing each other. The authors state that this system is frequent among professional colleagues who do not know each other well. For example, lecturers from different universities who are colleagues but not friends. International political protocol is also based on this system: equals from different governments meet but do not form unnecessarily close ties.

(ii) Solidarity politeness system $(-\mathrm{P},-\mathrm{D})$ : This system is characterized by symmetrical relations among equals and by closeness and familiarity. Therefore, participants use politeness strategies of involvement (positive politeness in Brown and Levinson's terms) with each other. This system is typical of conversations among friends, where the expression of solidarity and camaraderie is central.

(iii) Hierarchical politeness systems $(+\mathrm{P})$ : Social relations in this system are asymmetrical; participants recognize and respect the social differences that place a participant in a superordinate position over other(s). In unequal encounters, participants do not use the same type of politeness strategies in addressing each other: the participant in the 'dominant' position uses involvement strategies in speaking 'down' while the participant in the subordinate or 'inferior' position uses independence strategies towards his/her 'superior'. This system is frequent in business, governmental and educational organizations.

In our opinion, Scollon and Scollon's (1995) politeness systems are a useful addition to Brown and Levinson's paradigm in teaching politeness. However, it would be simplistic to view the notion of systems and the sociological variables which characterize them and, for that matter, social relations in general, as stable. Human communication is very complex and dynamic and more than three interactional possibilities exist. Besides, as we have pointed out in discussing the variables power, social distance and affect, and ranking of imposition, these are very complex and thorough studies of their influence and the ways in which they constrain language use must be carried out.

For example, Torreblanca-López and Garcés-Conejos (1996) and GarcésConejos and Torreblanca-López (1997) explore the type of interaction found in classroom discourse and provide an elaborate analysis of the power differential typical of this setting. Their starting point is Lakoff's (1989) claim that 
classroom discourse is an example of the type of informative discourse where politeness is given little, if any, importance. However, after a discussion of the power variable and an empirical analysis of this type of discourse, they conclude that teachers use lexical means of mitigation and therefore are oriented towards face relations and politeness. They view this genre as involving shared power by the participants: the institutional, overt power of the teacher is found to be in opposition to the covert power of students. Although at the level of overt power they find Scollon and Scollon's (1995) hierarchical politeness system to be in operation, it is the students' covert power that accounts for the selection of the compensatory strategies used by the teacher. The teacher uses politeness strategies in evaluating students' responses according to the positive and negative effects his/her evaluation can have on the students. GarcésConejos and Torreblanca-López (1997) find involvement strategies in positive evaluations and mainly independence strategies in negative evaluations, and relate these findings with the effort teachers make to lower the affective filter and promote participation and language learning.

Notwithstanding this point, we do believe that (i) we can teach students to express solidarity and deference, and therefore, to act in linguistically appropriate ways in equal and unequal encounters; (ii) that these behaviours have consequences for the linguistic forms chosen in each type of encounter; and (iii) that students can be made aware that different genres require different linguistic expressions of solidarity, deference or hierarchy. Our illustration of the teacher's use of politeness strategies in classroom discourse emphasizes the need to view notions of genre, Scollon and Scollon's (1995) systems and, for that matter, the expression of solidarity, deference and hierarchy, as dynamic and negotiable. These are constrained by complex cultural and socio-cognitive factors such as power, social distance and affect, the degree of imposition, as well as by the positive or negative effects that the propositional content of a face threatening act can have on the hearer.

Thus, we believe that genre-specific awareness-raising tasks are essential for the development of learners' pragmatic knowledge. Once learners become aware of the different social relations in various genres, and of the types of linguistic differences that can be expected across genres, their ability to observe and analyse new situations should be exploited. In this way, teachers can promote autonomous learning. Learners can be encouraged to become observers, ethnographers, since they are equipped with the tools needed to understand the linguistic encoding of social relationships, and to make informed choices in producing and interpreting meanings. ${ }^{5}$ 


\section{A methodological proposal}

In an attempt to capture all the ideas developed regarding the teaching of pragmatic knowledge, and more specifically, of sociolinguistic knowledge, we propose an awareness-raising task that has the following objectives:

(i) to raise learners' awareness of the different uses of linguistic devices that accrue from variation in the sociological variables that characterize the social relations of participants from one genre to another;

(ii) to sensitize them to the differences and similarities between two cultures, and to how these can be derived from the generic analysis of linguistic politeness devices;

(iii) to facilitate means of comparison;

(iv) to promote discussion and reach conclusions; in-class discussions and conclusions should be teacher-guided or, at least, contrasted with - and always supplemented by - information provided by the teacher;

(v) to promote autonomous learning by encouraging learners to observe situations, to become ethnographers when they have to engage in real encounters, in such a way that they develop the ability to identify particular linguistic choices appropriate to new situations in new cultures and can participate in these new situations confidently.

The methodological steps of our awareness-raising task to attain the above objectives are as follows. The first step would be to define politeness. Most students are totally unaware of what linguistic politeness is and tend to identify it with etiquette or good manners. Politeness as a cultural and socio-cognitive construct is defined here as the linguistic codification of social interaction pervasive in any kind of discourse. Even when speakers are deemed to be deliberately impolite or neutral to politeness considerations, they can only be so assessed by recourse to the notion of appropriateness which tells us what can be expected by participants in a given interaction in a given culture (GarcésConejos 1993; Fraser 1990).

The second step is to introduce students to Brown and Levinson's (1987) descriptive account of the lexico-syntactic and prosodic realization of linguistic politeness. Once the students are familiar with it, they will be encouraged to think about how it functions and to examine linguistic politeness in their own language and culture. This task should make students aware of the pervasiveness of linguistic politeness.

Thirdly, students should be introduced to Scollon and Scollon's (1995) politeness systems as a complement to the analysis of the sociological variables identified by Brown and Levinson. Students should discuss different types of interaction in their own culture and try to establish which of the three systems proposed by Scollon and Scollon (1995) would account for them. 
Next, short excerpts of texts should be analysed in the target language. These should be as varied as possible and belong to different genres: from ordinary conversation to academic writing (Bou-Franch 2001). At this point, students should be made aware of how the choice by interlocutors of different formal realizations of politeness provided by Brown and Levinson's framework is constrained by genre and by the given politeness system in which participants situate themselves.

Although most approaches to politeness focus on production, students should become aware that being polite does not only involve appropriate linguistic production, but also an appropriate response by listeners. Active listening in accordance with the expectations of the target culture is fundamental for appropriate polite behaviour and is a necessary condition for the successful realization of conversational exchanges (Garcés-Conejos and Bou-Franch to appear). This is something that students can observe by taking a close look at the different responses of parties in conversation to signal a greater or lesser degree of involvement, agreement, disagreement, desire to take the floor or encouragement to current speaker to continue talking, among others. Once again, these expectations should be compared to those in their own language and culture.

Finally, as politeness realizations are culture bound, students should also be made to reflect on the fact that different cultures may favour different politeness strategies and levels for the same situations. A useful guideline, if taken with as much open-mindedness as possible, is the notion of positive-politeness oriented cultures and negative politeness-oriented cultures. Understanding politeness and language use as the surface realizations of deep cultural values is fundamental. From this point of view, students are made aware that there are not more or less polite societies or languages but just different means to achieve the same ends.

After awareness-raising tasks such as the one suggested here, representative of a direct approach to teaching pragmatic knowledge, the teacher could present students with other activities that focus on the strategies or micro-skills tackled in class during the analysis and discussion of the texts. The teacher can also prepare role-plays and other communicative activities that give learners the opportunity to practise interaction, combining and complementing the awareness-raising tasks with other tasks used in the indirect tradition of teaching pragmatics.

In sum, we believe that linguistic politeness theory is an optimal tool to teach, explain and understand social interaction and to provide an insight into what constitutes appropriate linguistic behaviour in different genres and cultures. 


\title{
7. Conclusion
}

Throughout this article we have argued that a direct approach to teaching pragmatic knowledge should be taken as a starting point, and then combined afterwards with indirect practice of specific skills and strategies. More specifically, we have argued that linguistic politeness constitutes the most suitable tool with which to approach the teaching of L2 sociopragmatics in the classroom context. We have also explained how to use Brown and Levinson's (1987) model of politeness in foreign language instruction, relating it to genre analysis and politeness systems.

It is our belief that by promoting learners' sociopragmatic and pragmalinguistic knowledge, we will enhance their awareness of socio-cultural differences and therefore help them make informed choices in producing language and arriving at intended inferences in comprehension.

This, in turn, should help non-native speakers to become aware of potential areas for negative pragmatic transfer and avoid pragmatic failure. As Thomas (1983: 110) says, "pragmatic failure [...] often passes unchecked by the teacher or, worse, it is attributed to some other cause, such as rudeness, and the student is criticized accordingly". Learners need to be able to present the desired image of themselves and at the same time, interpret their interlocutors' image as intended in social interaction (Bou-Franch 1998; Bou-Franch and GarcésConejos 1994).

In sum, we believe that our methodological proposal ultimately meets an important goal of foreign language teaching: "Language teaching [...] has the important task to help students situate L2 communicative practices in their socio-cultural context and appreciate their meanings and functions within the L2 community" (Kasper 1997: 7).

\author{
Universitat de València \\ <patricia.bou@uv.es> \\ Universidad de Sevilla \\ <pilar_garces@yahoo.com>
}

\section{Notes}

* We wish to thank our colleagues Marianna Chodorowska-Pilch and Nuria LorenzoDus, as well as IRAL's anonymous reviewers, for their valuable comments on previous versions of this work. Needless to say, we are responsible for any mistakes.

1. For a review, see Fraser (1990).

2. For a detailed critical account of the model, based on results from empirical research, see Garcés-Conejos (1991, 1995).

3. Only a short description of the three variables is provided here, but, as Brown and Levinson understood them, they need to be refined and elaborated. For example, the notion of rights and obligations developed further by Fraser (1980) and Fraser 
and Nolen (1981) is to be included under ranking of imposition (but cf. Thomas 1995). The notion of power is expanded in Thomas (1995). Garcés-Conejos (1991, 1995) argues in favour of breaking down the variable of social distance into familiarity or closeness on the one hand, and affect or liking on the other. Spencer-Oatey (2000) carries out a detailed analysis of the variables initially identified by Brown and Levinson (1987).

4. We follow Sperber and Wilson $(1986,1995)$ in their cognitive definition of 'context', although we incorporate social and interactional dimensions into our analysis of communication.

5. Lorenzo-Dus (2001), in her discussion of the teaching of compliments and compliment responses to Spanish learners of British English, also considers the benefit of encouraging learners to become observers.

\section{References}

Alcón Soler, Eva (2000). The role of conversational interaction in the development of a second language: Its application to English language teaching in the classroom. Australian Review of Applied Linguistics 16: 135-145.

Bachman, Lyle (1990). Habilidad lingüística comunicativa. In Competencia Comunicativa: Documentos Básicos en la Enseñanza de Lenguas Extranjeras, Miquel Llobera, Dell Hymes, Nancy Hornberger, Michael Canale, Henry Widdowson, Joseph M. Cots, Lyle Bachman, and Bernard Spolsky (eds.), 105-128. Madrid: Edelsa.

Bhatia, Vijay K. (1993). Analyzing Genre. Language Use in Professional Settings. London: Longman.

Bialystok, Ellen (1993). Symbolic representation and attentional control in pragmatic competence. In Interlanguage Pragmatics, Gabriele Kasper and Soshana Blum-Kulka (eds.), 43-57. Oxford: Oxford University Press.

Blum-Kulka, Soshana and Hadass Sheffer (1993). The metapragmatic discourse of AmericanIsraeli families at dinner. In Interlanguage Pragmatics, Gabriele Kasper and Soshana BlumKulka (eds.), 196-223. Oxford: Oxford University Press.

Bou-Franch, Patricia (1998). On pragmatic transfer. Studies in English Language and Linguistics 0: 5-19.

- (2001). Conversation in foreign language instruction. In Language Learning in the Foreign Language Classroom, Victoria Codina and Eva Alcón (eds.), 53-73. Castellón: Universitat Jaume I.

Bou-Franch, Patricia and Pilar Garcés-Conejos (1994). La presentación de la imagen en conversaciones entre hablantes nativas y no nativas de inglés. Pragmalingüística 2: 37-61.

Brown, Gillian and George Yule (1983). Discourse Analysis. Cambridge: Cambridge University Press.

Brown, Penelope and Stephen C. Levinson (1987). Politeness: Some Universals in Language Usage. Cambridge: Cambridge University Press.

Carter, Ronald and Michael McCarthy (1995). Grammar and the spoken language. Applied Linguistics 16: 141-158.

Celce-Murcia, Marianne, Zoltán Dörnyei, and Sarah Thurrell (1995). Communicative competence: A pedagogically motivated model with content specifications. Issues in Applied Linguistics 6: 5-35.

Christie, Frances (1999). Genre theory and ESL teaching: A systemic functional perspective. TESOL Quarterly 33: 759-763.

Dörnyei, Zoltán and Sarah Thurrell (1994). Teaching conversational skills intensively: Course content and rationale. ELT Journal 48: 40-49. 
Escandell-Vidal, M. Victoria (1998). Politeness: A relevant issue for relevance theory. Revista Alicantina de Estudios Ingleses 11: 45-57.

Fraser, Bruce (1980). Conversational mitigation. Journal of Pragmatics 4: 341-350.

- (1990). Perspectives on politeness. Journal of Pragmatics 14: 219-236.

Fraser, Bruce and W. Nolen, (1981). The association of deference with linguistic form. International Journal of the Sociology of Language 27: 93-109.

Freedman, Aviva (1999). Beyond the text: Towards understanding the teaching and learning of genres. TESOL Quarterly 33: 764-767.

Freedman, Aviva and Peter Medway (1994). Locating genre studies: Antecedents and prospects. In Genre and the New Rhetoric, Aviva Freedman and Peter Medway (eds.), 1-20. London: Taylor and Francis.

Garcés-Conejos, Pilar (1991). La ira y la cortesía: Codificación lingüística del cambio social en el teatro inglés de los años 60. Ph.D. diss., Universitat de València.

- (1993). Ejemplo práctico de pragmática literaria: Una propuesta metodológica multidisciplinar. In XI Congreso Nacional de Lingüística Aplicada, José M. Ruiz, Patrick Serrín, and Elena Gonzáles (eds.), 301-310. Valladolid: Universidad de Valladolid.

- (1995). Revisión crítica de algunos de los postulados de la teoría de la cortesía lingüística propugnada por Brown y Levinson. In Aspectes de la Reflexió $i$ de la Praxi Interlingüística, Carlos Hernández, Brigitte Lépinette, and Manuel Pérez (eds.), 43-62. Valencia: Universitat de València.

- (2001). The teaching of pragmatic aspects in the ESL/EFL classroom: A critical review. In Teaching English in a Spanish Setting, Hang Ferrer, Barry Pennock, Patricia Bou, Carmen Gregori, and Mar Martí (eds.), 79-94. Valencia: Universitat de València.

Garcés-Conejos, Pilar and Patricia Bou-Franch (to appear). A pragmatic account of listenership/ listeners: Implications for foreign language teaching.

Garcés-Conejos, Pilar, Patricia Bou-Franch, and Emilio García-Gómez (1992). Estudio pragmáticocontrastivo del diminutivo: Una propuesta metodológica. In Bilingüismo y Adquisición de Lenguas: Actas del IX Congreso Nacional de AESLA, Feli Etxeberria and Jesús Arzamendi (eds.), 247-257. Bilbao: Universidad del País Vasco.

Garcés-Conejos, Pilar and Antonia Sánchez-Macarro (1998). Scientific discourse as interaction: Scientific articles vs. popularizations. In Linguistic Choice across Genres, Antonia Sánchez and Ronald Carter (eds.), 173-190. Amsterdam: John Benjamins.

Garcés-Conejos, Pilar and M. Mar Torreblanca-López (1997). Estrategias de énfasis y mitigación en el discurso del profesor de inglés como L2. In Gramática y Pragmática, M. MartínezVázquez (ed.), 1-13. Huelva: G.I. de gramática contrastiva.

Gómez-Morón, Reyes (1998). Aproximación pragmática al estudio del género: La utilización de estrategias de cortesía en los artículos médicos y lingüísticos. Ph.D. diss., Universidad de Sevilla.

- (2001). La enseñanza del uso de la cita en el artículo de investigación: Una aproximación pragmática. In Teaching English in a Spanish Setting, Hang Ferrer, Barry Pennock, Patricia Bou, Carmen Gregori, and Mar Martí (eds.), 111-122. Valencia: Universitat de València.

Gregori-Signes, Carmen (2000). The tabloid talkshow as a quasi-conversational type of face-toface interaction. Pragmatics 10: 195-213.

Grice, Paul (1975). Logic and conversation. In Syntax and Semantics, vol. 3, Speech Acts, P. Cole and J. Morgan (eds.), 41-50. New York: Academic Press.

Jary, Mark (1998). Relevance theory and the communication of politeness. Journal of Pragmatics 30: $1-19$.

Kasper, Gabriele (1992). Pragmatic transfer. Second Language Research 8: 203-231.

- (1997). Can Pragmatic Competence be Taught? (NetWork no.6). URL: http://www.1ll.hawaii. edu/nflrc/networks/nw6. [Retrieved 11 June 2000]. Honolulu: Second Language Teaching Curriculum Center, University of Hawaii. 
Kerbrat-Orecchioni, Catherine (1997). A multilevel approach in the study of talk-in-interaction. Pragmatics 7: 1-20.

Lakoff, Robyn T. (1973). The logic of politeness; or, minding your p's and q's. In Proceedings of the Ninth Regional Meeting of the Chicago Linguistic Society, Claudia Corum, Cedric SmithStark, and Ann Weiser (eds.), 292-305. Chicago: Chicago Linguistic Society.

- (1989). The limits of politeness: Therapeutic and courtroom discourse. Multilingua 8: 101129.

Leech, Geoffrey N. (1983). Principles of Pragmatics. London: Longman.

Lorenzo-Dus, Nuria (2001). Applying cross-cultural speech act research to the EFL classroom: The teaching of compliment responses. In Teaching English in a Spanish Setting, Hang Ferrer, Barry Pennock, Patricia Bou, Carmen Gregori, and Mar Martí (eds.), 159-170. Valencia: Universitat de València.

Martin, James R. (1985). Process and text: Two aspects of human semiosis. In Systemic Perspectives on Discourse, James D. Benson and William S. Greaves (eds.), 248-274. Norwood, NJ: Ablex.

McCann, C. Douglas and E. Tony Higgins (1990). Social cognition and communication. In Handbook of Language and Social Psychology, Howard Giles and W. Peter Robinson (eds.), 13-32. Chichester: John Wiley and Sons.

McCarthy, Michael and Ronald Carter (1994). Language as Discourse: Perspectives for Language Teaching. London: Longman.

Meier, Ardith J. (1997). Teaching the universals of politeness. ELT Journal 51: 21-28.

Miller, Carolyn R. (1984). Genre as social action. Quarterly Journal of Speech 70: 151-167.

Richards, Jack C. (1990). The Language Teaching Matrix. Cambridge: Cambridge University Press.

Richards, Jack C. and Richard Schmidt (eds.) (1983). Language and Communication. London: Longman.

Sacks, Harvey, Emanuel A. Schegloff, and Gail Jefferson (1974). A simplest systematics for the organization of turn-taking for conversation. Language 50: 696-735.

Schegloff, Emmanuel A. (1999). Discourse, pragmatics, conversation, analysis. Discourse Studies 1: 405-435.

Schmidt, Richard (1993). Consciousness, learning and interlanguage pragmatics. In Interlanguage Pragmatics, Gabriele Kasper and Soshana Blum-Kulka (eds.), 21-42. Oxford: Oxford University Press.

Scollon, Ron and Suzanne W. Scollon (1995). Intercultural Communication: A Discourse Approach. Oxford: Blackwell.

Spencer-Oatey, Hellen (ed.) (2000). Culturally Speaking: Managing Rapport through Talk across Cultures. London: Continuum.

Sperber, Dan and Deirdre Wilson (1986). Relevance. London: Blackwell.

- (1995). Relevance. 2nd ed. London: Blackwell.

Swales, John (1990). Genre Analysis. English in Academic and Research Settings. Cambridge: Cambridge University Press.

Thomas, Jenny (1983). Cross-cultural pragmatic failure. Applied Linguistics 4: 91-112.

- (1995). Meaning in Interaction: An Introduction to Pragmatics. London: Longman.

Torreblanca-López, M. Mar and Pilar Garcés-Conejos (1996). La clase de inglés como L2: ¿Discurso interactivo o informativo? Una aproximación desde la teoría de la cortesía Lingüística. Babel-AFIAL 3-4-5: 123-143.

Wilson, Deirdre (2000). Metarepresentation. Course delivered in Vitoria, Universidad del País Vasco. 